\title{
EDITORIAL
}

\section{The social construction of mental illness ${ }^{1}$}

To what extent are mental disorders things-in-themselves; that is, entities determined by their intrinsic nature? How far are those disorders shaped by the very concepts physicians employ to define and classify them?

To some, such questioning will seem madness itself, a recursive doubt about the validity of clinical observation, one that can only undermine the pragmatics of practice. To others, recognizing how far the data of observation are determined by what patient and doctor believe to be true is fundamental to understanding the mutability of the clinical phenomena we encounter.

In taking the position that mental disorders are socially constructed, I have deliberately set out to challenge the conventional wisdom that medicine is simply an empirical discipline registering objectively what is 'out there' in nature. By so doing, I do not in the least imply that diseases would not exist as phenomena in the world if men did not recognize them. Indeed, it is precisely their existence that provides the necessity for trying to make sense of them if we are to diminish human suffering. However, the concepts we invent to account for disease come to shape not only the observations we make and the remedies we prescribe, but the very manifestations of disease itself. Concepts of pathophysiology are 'constrained fictions' - 'constrained' in that they must at least approximately match events in the world - 'fictions' in that their ability to make sense of those events, or even to predict them, does not establish that they correspond to the connecting principles of nature.

My argument will consist of four theses. First, that all scientific concepts are inventions of the imagination. Second, that the human sciences are beset by a paradox: what is believed to be true about behaviour affects the very behaviour which it purports to explain. Third, that the trajectory of illness is influenced by the beliefs patients and doctors hold about course and prognosis. Finally, that physicians, no less than their patients, are constrained by socially constructed roles.

\section{'THE CONNECTING PRINCIPLES OF NATURE'}

The notion that scientific concepts are inventions of the imagination was advanced by the economist and philosopher Adam Smith (1980) in a treatise on the History of Astronomy, first published in 1790. Smith contended that:

Philosophy is the science of the connecting principles of nature. Nature...seems to abound with events which appear solitary and incoherent with all that go before them; which therefore disturb the easy movement of the imagination; which make its ideas succeed each other...by irregular starts and sallies; and which thus tend...to introduce...confusions and distractions...

Philosophy, by representing the invisible chains which bind together all these disjointed objects, endeavours to introduce order into this chaos of jarring and discordant appearances, to allay this tumult of the imagination, and to restore it, when it surveys the great revolutions of the universe, to that tone of tranquillity and composure, which is both most agreeable in itself, and most suitable to its nature...

Let us examine, therefore, all the different systems of nature, which...have successively been adopted by the learned and ingenious; and... [inquire] how far each of them was fitted to soothe the imagination, and to render the theatre of nature a more coherent, and therefore a more magnificent spectacle, than otherwise it would have appeared to be' (pp. 45-46).

\footnotetext{
This editorial is based on the 1987 Upjohn Lecture, presented at the Department of Psychiatry, Oxford University, on 19 May 1987.

1 Address for correspondence: Professor Leon Eisenberg, Department of Social Medicine and Health Policy, Harvard Medical School, 25 Shattuck Street, Boston, Mass. 02115, USA
} 
In examining the 'different systems of nature...adopted by the learned and ingenious', Smith reviewed the succession of astronomical theories from the Greeks to Newton. Although each new account of the 'invisible chains' provided a more coherent explanation of the apparent motions of the heavens than its predecessor and for a time seemed to lay bare the actual celestial mechanism, it was in turn succeeded by a novel act of the imagination which belied the 'truth' men thought they had grasped. Smith concluded his treatise on astronomy with these worlds:

the system of Sir Isaac Newton [is one] whose parts are all more strictly connected together, than those of any other philosophical hypothesis. Allow his principle, the universality of gravity, and that it decreases as the squares of the distance increase, and all the appearances, which he joins together by it, necessarily follow... His system now prevails over all opposition...Even we, while we have been endeavouring to represent all philosophical systems as mere inventions of the imagination... have insensibly been drawn in, to make use of language expressing the connecting principles of this one, as if they were the real chains which nature makes use of to bind together her several operations (pp. 104-105, italics added).

Smith's caveat against misreading 'the inventions of [Newton's] imagination' as 'the real chains' of nature, a warning he himself found hard to keep in mind, has been amply justified by the radical transformations theoretical physics has undergone in our time. Yet Albert Einstein (1934), in an essay on the method of theoretical physics, found it necessary to write:

To the discoverer...the constructions of his imagination appear so necessary and so natural that he is apt to treat them not as the creations of his own thought but as given realities.

Neither Adam Smith nor Albert Einstein questioned the reality of material bodies and their motions in a universe altogether indifferent to human existence. If they emphasized that scientific efforts to 'introduce order into [the] chaos of jarring and discordant appearances' are uniquely human acts of creation, they never implied that the positions or motions of heavenly bodies are influenced by what we choose to believe. Indeed, when observation matches prediction, the coincidence is taken as evidence for the validity of theory. Thus the Royal Society of Astronomy laid careful plans to study the total solar eclipse of 1919 which provided a rare opportunity to test a proposition derived from the general theory of relativity. The astronomical observations yielded data compatible with the interpretation that rays of light from distant stars had been deflected by the sun's gravitational field, just as had been predicted. In responding to those findings, the President of the Royal Society, Sir J. J. Thomson, heralded Einstein's theory as 'one of the greatest achievements in the history of human thought' (Frank, 1947). There was no reason then, nor is there any reason now, for supposing that the physical properties of sun, stars or light had been altered by the theories of field and force constructed to account for them.

\section{PREDICTION IN SOCIAL SCIENCE}

If the cosmos remains sublimely indifferent to the beliefs held by physicists, such is not the case for the relation between social theory and the human behaviour it purports to explain. In the terse aphorism of the sociologist, W. I. Thomas: 'If men define situations as real, they are real in their consequences.'

Social and behavioural scientists suffer from the reciprocal of Cassandra's curse. You will recall that the daughter of Priam, the last king of Troy, was granted the gift of prophecy by the god Apollo on condition of fulfilling his desires. When she obstinately refused him her favours, he took revenge by adding the proviso that no one would believe Cassandra's prophecies. The problem for social scientists is quite the opposite: because we may be believed, and often are, our theories become part of the 'connecting principles' we seek to discover.

The manpower economist, A. M. Carrter (1971), predicted a surplus of scientists and engineers by extrapolating from the numbers in training and by anticipating trends in the job market. He proved to be wrong, not because his arithmetic was wrong, it wasn't, but because students and their faculty advisers believed what he, and others, wrote. The consequence of that belief was that fewer 
students entered graduate training and the expected surplus became a deficit. If he had been a prophet without honour, history would have proved him right!

The physician, like the social scientist, is honoured, believed - but misled by success rather than failure! As an intern, I 'saw' patients with chronic brucellosis, a disease diagnosed on the basis of weakness, fatigue, migratory aches and pains and low grade fever; a history compatible with exposure to Brucella; and a positive agglutinin titre. It was considered rather a coup to have made the diagnosis; the patient tended to be grateful, despite the absence of effective treatment, having previously been dismissed as a hypochondriac or a malingerer. Yet, thirty years later, it is reasonably clear that chronic brucellosis is a spurious disease construct which legitimizes and thereby perpetuates chronic illness behaviour.

Comparisons of fully recovered patients with those complaining of persistent symptoms after bacteriologically confirmed acute brucellosis reveals no difference on physical examination or laboratory tests (Cluff et al. 1959). However, on mental status examination, the symptomatic patients display signs of depression. Are the symptoms somatized depression or are patients depressed for having a chronic bacterial disease?

To discriminate between the two possibilities, Imboden and his colleages (Imboden et al. 1961) assessed 480 male civil service workers by the Minnesota Multiphasic Personality Index shortly before an expected epidemic of influenza. During the 'flu season, the rate of infection (as determined by serological surveillance of all subjects) was no greater in persons identified as "psychologically vullnerable' by their test scores, but they made clinic visits five times more often. Almost all the patients who exhibited prolonged convalescence from 'flu were in the vulnerable group. The chronic aftermath of acute infection represents a pattern of persistent illness behaviour precipitated by a disease episode in psychologically vulnerable individuals. Once sanctioned by a physician, the symptoms are more likely to persist; the persistence of the symptoms is mistaken for confirmation of the diagnosis.

Chronic brucellosis no longer has much cachet as a diagnosis, but candidates for the succession are very much in evidence. Currently, considerable attention is being devoted to "chronic mononucleosis', also known as 'chronic active Epstein-Barr virus (EBV) infection'. The syndrome is characterized by chronic fatigue, fever, myalgia, pharyngitis, headache, depression and cognitive change (Buchwald et al. 1987; Holmes et al. 1987). Antibody titres against EB virus are somewhat higher in patients with these symptoms than they are in the general population, but exposure to EBV is so ubiquitous that there are no cut-off levels which reliably distinguish patients from controls. Whatever the cause of this symptom pattern, EBV infection is an unlikely bet. If some cases indeed prove to be due to an as yet to be discovered virus, many more, in my estimation, represent the somatization of personal distress, legitimized by a newly fashionable diagnosis.

\section{THE SOCIAL CONSTRUCTION OF PROGNOSIS}

Beliefs about mental disorders are real in their consequences for the behaviour of patients, psychiatrists and society. Recall the extraordinary clinical manifestations in the patients Charcot diagnosed as suffering from hysteria. Repeatedly put on display to international audiences assembled in the amphitheatre of the Salpêtrière Hospital, they would reliably enact a spectacular range of pathological phenomena from dysaesthesias through pseudo-epileptic fits to opisthotonos (Veith, 1965). The patient brought to see Professor Charcot knew she was being examined by a formidable personage. Once Charcot had diagnosed Mlle X or Mme Y as a hysteric, he would unwittingly choreograph her performance. What he expected, she enacted; what she enacted confirmed his conviction. A century later, the diagnosis of hysteria is made much less often, the performance is far less flamboyant, and the term 'hysteria' itself has been deleted from DSM-III nomenclature, having been replaced by 'conversion disorder'.

If the case of hysteria provides an example of a disorder whose definition sculpted its features, perhaps it will be dismissed as sui generis; what is true for hysteria need not apply to the major mental disorders. How far can similar claims be made about schizophrenia? Here, the evidence is 
more ambiguous but none the less suggestive. Let us begin with the findings of the WHO International Pilot Study of Schizophrenia (World Health Organization, 1973).

In nine countries chosen for the contrast between their cultures, patients were diagnosed as schizophrenic on the basis of standardized interviews and agreed-upon criteria at each of the participating centres. At follow-up five years later (World Health Organization, 1979), there were striking differences from one country to another in the clinical outcome of the patients, all of whom ostensibly suffered from the same disorder. Patients in the developing countries (Nigeria, India, Colombia) exhibited a considerably more favourable course than did patients in the industrialized world (US, USSR, UK and Denmark), an entirely unexpected result in view of the readier availability of 'modern' treatment in the latter. However, the interpretation of the observed differences in outcome is uncertain because the patients were not necessarily representative of the population of schizophrenics in each country. Variations in outcome by site might have been due to unascertained differences in sampling frames.

In consequence, Norman Sartorius and his colleagues at WHO undertook a second study (Sartorius et al. 1986), this time centred on the clinical determinants of outcome. Investigators at 12 research centres in 10 countries monitored all first contacts by patients aged from 15 to 54 years who sought help for symptoms of psychotic illness. The screening process yielded a sample of almost 1400 persons meeting broad inclusion criteria for schizophrenia and related non-affective disorders as defined by the International Classification of Disease. At two-year follow-up, a significantly higher percentage of the patients in developing countries exhibited a 'mild' course than did patients in developed countries $(56 \% v$ v. $39 \%)$; the converse was true for patients with a 'severe' course $(24 \% v .40 \%)$. Although, as expected, patients with acute onset had a more favourable outcome than those with gradual onset in all settings, the better prognosis in developing countries was not accounted for by type of onset; both acute and gradual-onset patients did better in developing countries.

Although the authors chose to emphasize that 'patients with the diagnosis of schizophrenia in the different populations and cultures share many features at the level of symptomatology' (p. 926), the differences are no less significant than the similarities. Within the category of schizophrenia, the use of individual ICD subtypes from one centre to another varied from 0 to $65 \%$. 'Acute' was employed almost twice as often as 'paranoid' and 'catatonic' as 'hebephrenic' in developing countries; the reverse was true in developed countries. At the level of symptoms recorded by the Present State Examination (PSE), patients in developing countries exhibited a lower frequency of depressive symptoms, delusional mood and thought insertion and a higher frequency of auditory and visual hallucinations. Thus the clinical presentation of disorders conforming to a broad concept of schizophrenia displayed country-by-country variations that are moulded by the cultural envelope. For our topic, what is noteworthy is the robustness of the original finding of better outcome in developing countries; in the replication, it holds up after controlling for mode of onset. How can we account for this surprising difference?

It is tempting to suppose that the toleration for impaired behaviour is greater in developing societies because of less stringent vocational demands (i.e. sharehold farming and cottage crafts versus agro-business and industrial production lines). This, however, grossly underestimates the complex role demands stemming from caste, kinship, religious, sex and age stratification in such societies. It is our ethnocentrism and the persistence of a colonial mentality that leads to the characterization of such societies as 'simpler' or 'less stressful' than our own.

Her own studies of patients and healers in Sri Lanka have led Nancy Waxler (1979) to emphasize two aspects of the culture of peasant societies: first, local beliefs about the cause and course of mental illness and, second, the response of the patient's kinship to deviant behaviour. In Sri Lankan villages, insanity is ascribed to causes external to the individual, usually supernatural; the illness is regarded as a threat to the family as well as to the patient. To oversimplify the argument, if a disorder is 'explained' by spirit possession, then it is not intrinsic to the patient; once appropriate ritual exorcizes the demons, the patient is restored to his or her former self. This is in contrast to the Western view of schizophrenia as a chronic biological disorder and of the recovered patient as 
being 'in remission' rather than 'cured'. Thus, belief creates the expectation of complete restoration to the status quo in the one culture and of persisting impairment in the other. Note that this hypothesis attempts to explain the maintenance of chronicity rather than the genesis of disorder.

Her second point stresses differences in family response and mode of treatment in the two worlds. Whereas the individual, at least until recently, has been the unit of treatment in the West, the family is the unit in the traditional world. The appearance of illness in the patient demands a response from family and kinship group to an event which threatens its integrity. Healer and family join in solidifying kinship obligations and in redefining group boundaries. With social tensions diminished, it is contended, there is no further 'need' for the deviant behaviour, and social expectations press the patient towards normality.

Admittedly, this is an oversimplification. All mental illness does not resolve in developing societies. The very concept of a unitary peasant culture is an abstraction from the reality of pluralistic health belief systems in rural societies no longer isolated from Western ideology (Eisenberg \& Kleinman, 1981). Clausen's studies of schizophrenic patients in the US make it clear that labelling occurs late in the course of an evolving thought disorder and has less impact on reintegration in the community than does the persistence of deviant behaviour (Clausen, 1981). Yet the rediscovery of the moral treatment of the insane in the UK (Wing \& Brown, 1970) and the US (Gruenberg, 1967) provides abundant evidence that many of the symptoms displayed by patients hospitalized in large, impersonal and faceless institutions result from the institutional environment rather than from the disorders present at admission. Furthermore, we have come to recognize that family influences have a powerful effect on the course of illness.

Brown and his colleagues were the first to demonstrate (Brown et al. 1962, 1972) that the likelihood of relapse in schizophrenic patients discharged from hospital is significantly greater among patients returning to a family characterized by high 'expressed emotion' (EE), an index based principally on the frequency of critical comments during a structured interview with a key family informant. The power of the family environment is indicated by the observation that the number of hours per week in actual face-to-face contact with high EE relatives is decisive; if contact is less than 35 hours a week, the likelihood of relapse is half as great. When intervention with families succeeds in lowering EE, the relapse rate of patients declines in parallel (Leff et al. 1985). Randomized controlled trials in the US have confirmed that family treatment based on these principles augments the power of neuroleptics to enable chronic schizophrenics to maintain themselves in the community (Falloon et al. 1982, 1985). A link between these studies in the West and findings in developing societies is suggested by a recent report on Mexican American families in Los Angeles (Karno et al. 1987). Once again, high family EE predicted relapse in remitted schizophrenics; at the same time, the investigators found that overall levels of EE were lower in Hispanic than in Anglo households. Just what aspects of family interaction captured by the high EE label make a difference to outcome is not clear; caution is warranted before our generation of psychiatrists victimizes families (Kanter et al. 1987) by adding guilt to misfortune, as our predecessors did by condemning mothers as 'schizophrenogenic'.

The effect of the social environment on manifestations and course does not make schizophrenia a 'myth', notwithstanding the contrary opinion of Thomas Szasz. Refusing to acknowledge its existence or changing its name will not make it go away. The way we formulate the diagnosis and the way society responds to patients with the disorder do have consequences for course and outcome. That is the message in the data. To speak of 'the natural history' of schizophrenia - or any other disease, for that matter - is to employ a misleading phrase which implies the unfolding of intrinsic biological determinants. What the course of disease reveals is its social history; that is, the features which characterize it at a given time, in a given community. Course and outcome, for both patient and family, are determined by the meaning which the culture ascribes to the disease, by the treatments to which the patient has access, and by the pathology of the disease process, itself an outcome of the interaction between the noxious agent(s) and host resistance. Disease, Virchow pointed out, is life under altered circumstances. Our task is to ascertain and reverse those circumstances. 


\section{THE SOCIAL ROLE OF MEDICINE}

Thus far, the emphasis has been on the ways in which theories advanced by professionals, once they have diffused into popular culture or have been conveyed directly to the patient by the authority of the physician, shape symptoms, course and outcome in illness. The professional: lay boundary is, however, permeable in both directions; the cultural beliefs and values professionals share with other members of the community determine what doctors do and what they think they do. Physicians, like traditional healers, fulfil assigned social roles cloaked by the rationale of professional ideology.

Stone (1979) argues persuasively that the illness label, as applied by physicians, has become an ever more widely used administrative device for rationing the benefits provided by public programmes. In effect, physicians are employed as gatekeepers. Illness-tested benefits include direct monetary transfer programmes (disability, workmen's compensation, etc.), custodial care institutions (today's equivalent of last century's almshouses) and exemptions from military service. In fashioning the US Social Security Disability programme, the Advisory Council recommended that 'compensable disabilities be restricted to those which can be objectively determined by medical examination or test' (Stone, 1979, p. 513). By this means, benefits were to be limited to the deserving, and the rest of us would be kept at work. Confidence in assessing disability by 'objecive determination' cannot be sustained in the face of a vast literature on disagreement between doctors and the extent to which doctors' judgements are influenced by who employs them (i.e. management or labour). Whatever is decreed by legislation, medical estimates of physical impairment account for much less of the variance in work disability than do the nature of the job itself and the social organization of the workplace (Yellin et al. 1980).

During recent decades, there has been a disproportionate growth in the US in disability benefit payments, in comparison with payments based on economic need or age. Stone argues that reliance on the disability system serves latent political control functions. Applications for disability insurance increase during periods of high unemployment; medical certification may serve to reduce political tension. Efforts to ratchet down on eligibility standards have become a battleground between conservatives and liberals in the current era of budget deficits. In the military draft during the Vietnam war, medical exemption provided a mechanism by which middle- and upper-class youths were able to avoid service; the armed forces became disproportionately lower-class and Black. Whatever the criteria by which they decided that their patients were unfit for duty, physicians, many of them psychiatrists, served the extra-medical interests of one class of society, sometimes wittingly, sometimes not.

If the physician is often unaware of his role as the gatekeeper for social benefits, control over physician behaviour by the insistent demands of the community is glaringly evident in the cascade of events which followed a sensational crime in New York City.

On 7 July 1986, Juan Gonzalez, a homeless 43-year-old Cuban refugee, slew two passengers and wounded 9 others with an ornamental sword on a Staten Island ferry boat (McFadden 1986). The tragedy became a source of public outrage when newspapers reported that Gonzalez had been seen on 3 July in the psychiatric emergency room of the Presbyterian Hospital, the teaching hospital of Columbia University. He had been brought to the emergency room by the police for threatening people as he shouted 'Jesus wants me to kill'. Front-page news stories that week questioned the clinical judgement of the psychiatric residents who had discharged him to out-patient care on 5 July (after failing to find a bed for him at their own or seven other psychiatric hospitals). The accounts suggested that financial considerations may have been the motor behind the decision to discharge an impecunious patient. The New York State Commission on Quality of Care for the Mentally Disabled investigated the incident and concluded that the care of the patient 'did not meet professional standards', and that there had been 'inadequate supervision' of the residents (Sullivan, $1986 a$ ).

Whatever the truth of these accusations (they are disputed by the hospital), what is not in question is the sequence of events which followed the publicity accorded to the murders. Before the 
end of July (Sullivan, 1986b), the number of patients seen each week in psychiatric emergency rooms in New York City had increased from 1100 to 1500 ; the number who were admitted to municipal hospitals led to such overcrowding that patients were being transferred by bus and van to back-up state mental hospitals. By mid-August (Sullivan, 1986c), psychiatric patients 'no longer considered dangerous or troublesome' were being held in unused medical or surgical beds. By midNovember (Sullivan, 1986d), the state had called on private psychiatric hospitals to expand their facilities for involuntary admission of emergency patients and even agreed to underwrite renovation costs. The crisis did not remit until early spring, when municipal hospital psychiatric services settled back into their ante-bellum status, barely managing the tide of human misery washed up on their shores (Cancro, R., personal communication).

What had happened? Was the Gonzalez episode a sentinel event in a municipal epidemic of homicidal psychoses? Hardly! What had changed were the administrative decisions made about the very same troubled and troublesome persons who had been on the city streets in the weeks and months before panic erupted. In response to a public perception of dangerous lunatics prowling the streets and endangering innocent citizens, the police brought a much higher proportion of verbally belligerent persons to emergency rooms, no longer willing to gamble that they would not act on their threats; psychiatrists, equally fearful of a Type-II error, put more of the persons brought to the emergency rooms behind locked doors.

The psychiatric resident who had discharged Gonzalez had been pilloried in the press; his supervision had been termed inadequate; his hospital stood accused of malfeasance. From that day on, residents on emergency duty no longer permitted potentially violent patients to leave without an evaluation by a senior physician, a change itself producing longer queues in the emergency rooms. The staff psychiatrist, like the trainee mindful of the public outcry, opted to be on the 'safe side' by hospitalizing the very patients who the day before would have been referred for out-patient care. What had occurred was not an epidemic of homicidal psychosis but an epidemic of panic among the gatekeepers.

Amidst the crisis of overcrowding, a New York Times editorial (Editorial, 1986) criticized the rush to hospitalization as 'the practice of defensive medicine' and pointed to de-institutionalization as the real culprit. Until the huge imbalance in the distribution of resources between hospital and community systems was remedied, the editorial concluded, 'the state's mental health officials can only choose which to abuse, patients' rights or public safety'. There were two small problems. First, New York state authorities announced in the very same month their plan to 'reduce by a third' the number of patients in mental hospitals over the coming decade. The Deputy Commissioner refused to call the programme de-institutionalization lest it 'be painted with an old brush'. He stated coyly: 'We prefer to call it a reconfiguration of services' (Sullivan, 1986e). Secondly, the Times editorial implied that patients presented a danger to public safety, a danger, furthermore, that could be averted by proper diagnosis and treatment.

The fact is that predicting dangerousness is more magic than science (Monahan, 1981; Steadman, 1983). In a recent study, whose findings they report as more encouraging than most, Sepejak et al. (1983) examined the relationship between clinical predictions of dangerousness, and actual behaviour over the next two years, in some 400 persons brought to the Metropolitan Toronto Forensic Service. Psychiatric predictions proved to be correct $60 \%$ of the time. The result is unimpressive, despite its 'statistical significance'; their own data indicate that a history of violent offences by itself predicts correctly $57 \%$ of the time and a history of previous incarceration $56 \%$ of the time!

Ill-equipped as we are for predicting violence, society has assigned the task to us in lieu of other likely candidates. We have been thrust into a game with high stakes and asymmetric consequences. A 'miss' by the psychiatrist puts him at risk for public condemnation, possible loss of job and perhaps even a suit from the victim of the violence, whereas a false 'hit' is unfortunate only for the patient unnecessarily hospitalized. It takes no Nostradamus to predict what a prudent doctor will do to minimize losses under such circumstances.

True, there have been no other such episodes in the 10 months that followed the ferry-boat 
killings. But neither were there any in the 10 months before it. Killings by psychotic persons are statistically uncommon and constitute a small minority of urban murders. The city was no safer for the draconian action of locking away hundreds of persons who posed more of a threat to themselves than to others, but psychiatrists working in municipal emergency rooms were at less risk for punishable error.

The slayings on the ferry-boat, the panic provoked by the media, the defensive responses of the hospital system, and the misfortune visited upon patients bring into crude relief a medical gatekeeper function ordinarily out of public sight and professional mind. The fact is that the definition and management of illness is a fundamental social control mechanism in all societies (Unschuld, 1986). In this respect we do not differ from pre-literate peoples, like the Ndembu of rural Zambia. Their culture regarded all misfortunes, including sickness, as punishments meted out by ancestral spirits for violations of basic group norms. Healers were called upon to unmask the causes of conflict within and between tribes. Although healing rituals were expected to lead to the patient's recovery, their key purpose was preventive: protecting the community against continuing misfortune. The anthropologist Victor Turner has described the role of Ndembu healing in terms which illuminate the ritual functions assigned to physicians in 'modern' society:

The sickness of the patient is mainly a sign that 'something is rotten' in the corporate body. The patient will not get better until all the tensions and aggressions in the group's interrelations have been brought to light and exposed to ritual treatment (Turner, 1967).

The diviner is a man who redresses breaches in the social order, enunciates moral law, detects those who secretly and malevolently transgress it, and prescribes remedial action (Turner, 1975).

\section{CONCLUSION}

To recognize that scientific theories are inventions of the imagination is to enhance rather than to diminish their grandeur. It is, however, their very success in introducing order into the chaos of appearance that makes it easy to mistake them for reality itself. For the clinician as scientist, the problem is compounded: the more he is believed, the more his prophecies become self-fulfilling. Accounts of disease, through the expectations they arouse, impact on the course of disease. If professional ideology influences society, it also profoundly reflects the values of the society in which it is embedded.

There is no escaping the paradox except to recognize it as such. The more we keep in mind that individuals no less intelligent than ourselves, in other times and at other places, have come to very different but equally coherent descriptions of the world of things and of people, the more we can correct for the effect of where we stand on what we see. What distinguishes one description of the universe from another is not any final correspondence with the real chains of nature but its efficacy for human purposes. The clinician who understands that he is a participant in, as well as an observer of, the drama of health and sickness will be better able to fashion new remedies for old problems.

This is far from the stance of cultural relativism. To acknowledge that 'magical' explanations of disease are no less internally coherent than 'scientific' ones in no way denies the far greater power of the latter for prevention and cure. It does emphasize that theories of behaviour are not simply statements about the connections between 'facts', they are statements which change 'facts' and have profound moral implications for the role of human agency in the cause, persistence and cure of mental disorders.

L. EISENBERG

\section{REFERENCES}

Brown, G. W., Monck, E. M., Carstairs, G. M. \& Wing, J. K. (1962). Influence of family life on the course of schizophrenic illness. British Journal of Preventive and Social Medicine 16, 55-68.

Brown, G. W., Birley, J. L. T. \& Wing, J. K. (1972). Influence of family life on the course of schizophrenic disorders: a replication. British Journal of Psychiatry 121, 241-258.

Buchwald, D., Sullivan, J. L. \& Komaroff, A. L. (1987). Frequency of 'chronic active Epstein-Barr virus infection' in a general medical practice. Journal of the American Association 257, 2303-2307. 
Carrter, A. M. (1971). Scientıfic manpower for 1970-1985. Science 172, $132-140$

Clausen, J. (1981). Stigma and mental disorder: phenomena and terminology. Psychiarry 44, 287-296.

Cluff, L. E., Trever, R. W., Imboden, J. B. \& Canter, A. (1959). Brucellosis. II. Medical aspects of delayed convalescence. Archives of Internal Medicine 103, 398-405.

Editorial: Delusions about mental health. (1986). New York Times, 1 August.

Einstein, A. (1934). On the method of theoretical physics. Phulosophy of Science 1, 162.

Eisenberg, L. \& Kleınman, A. (eds.) (1981). The Relevance of Social Science for Medicine, pp. 8-11. Reidel: Boston.

Falloon, I. R. H., Boyd, J. L., McGill, C. W., Lazanı, J., Moss, H. B. \& Gilderman, A. M. (1982). Family management in the prevention of exacerbations of schizophrenia : a controlled study. New' England Journal of Medicine 306, 1437-1440.

Falloon, I. R. H., Boyd, J. L. \& McGill, C. W. (1985). Family management in the prevention of morbidity of schizophrena: clinical outcome of a two-year longitudinal study. Archives of General Psychiatry 42, 887896.

Frank, P. (1947). Einstein, His Life and Times, pp. 140-142. Knopf: New York.

Gruenberg. E. M. (1967). The social breakdown syndrome: some origins. American Journal of Psychiatry 123, 1481-1489.

Holmes, G. P., Kaplan, J. E., Stewart, J. A., Hunt, B., Pinsky, P. \& Schonberger, L. (1987). A cluster of patients with a chronic mononucleosis-like syndrome is Epstein-Barr virus the cause? Journal of the American Medical Association 25, 2297-2302.

Imboden, J., Canter, A. \& Cluff, L. E. (1961). Convalescence from influenza. Archives of Internal Medicine 108, 393-399.

Kanter. J., Lamb, H. R. \& Loeper, C. (1987). Expressed emotion in families: a critical review. Hospital and Community Psychiatry 38 , 374-380.

Karno, M., Jenkıns, J., de la Selva, A., Santana, F., Telles, C., Lopez, S. \& Mintz, J. (1987). Expressed emotion and schizophrenic outcome among Mexican-American families. Journal of Nervous and Mental Disease 175, 143-151.

Leff, J. P., Kuipers, L. \& Berkowitz, R. (1985). A controlled trial of intervention in the famulies of schizophrenic patients: a two-year follow-up. British Journal of Psychiatry 146, 594-600.

McFadden, R. D. (1986). Man with a sword kills two on Staten Island ferry. New York Times, $8 \mathrm{July}$

Monahan, J. (1981). The Clinical Prediction of Violent Behavior. DHHS No. (ADM)81-921: Washington, D.C.

Sartorius, N., Jablensky, A., Korten, A., Ernberg, G., Anker, M., Cooper, J E. \& Day, R. (1986). Early manifestations and first- contact incidence of schizophrenia in different cultures. Psycho. logical Medicme 16, 909-928.

Sepejak, D., Menzies, R. J., Webster, C. D. \& Jensen, F (1983). Clinical predictions of dangerousness. two-year follow-up of 408 pre-trial forensic cases Bulletin of the American Academy of Psychiatry and Law 11, 171-181.

Smith, A. (1980) In Essays on Philosophical Subjects (ed. W. P. D. Wightman and J. C. Bryce), pp. 45-46; 104-105. Clarendon Press: Oxford.

Steadman, H. J (1983). Predicting dangerousness among the mentally ill: art, magic and science. International Journal of Law and Psychiatry 6, 381-393.

Stone, D. A. (1979). Diagnosis and the dole: the function of tllness in American distributıve politics. Journal of Health Politics, Policy and Law 4, 507-521.

Sullivan, R. (1986a). State panel criticizes emergency psychiatric care New York Times, 3 August.

Sullivan, R. (1986b). Psychiatric treatment surging since ferry killings. New York Times, 25 July.

Sullivan, R. (1986c). City is planning a shift of psychiatric patients. New York Times, 14 August.

Sullivan, R. (1986d). State asking hospitals to add psychiatric beds. New York Times, 14 November.

Sullivan, R. (1986e). State seeks cut in psychiatric patients. New York Times, 17 August.

Turner, V. (1967). The Forest of Symbols, p. 392. Cornell University Press: Ithaca.

Turner, V. (1975) Revelation and Divinatton in Ndembu Ritual, pp. 241-242. Cornell University Press Ithaca

Unschuld, P. (1986). The conceptual determination of individual and collective experiences of 1 llness. In Concepts of Health, Illness and Disease (ed. C. Currer and M. Stacey), pp 51-70. Berg: New York.

Vetth, I. (1965). Hysteria the Hustory of a Disease, pp. 228-246. The University of Chicago Press. Chicago

Waxler, N. E. (1979). Is outcome for schizophrenia better in nonindustrial societies? The case of Sri Lanka. Journal of Nervous and Mental Disease 167, 144-158.

Wing, J. K \& Brown, G.W. (1970). Institutionalism and Schizophrenia. Cambridge Unıversity Press: Cambridge.

World Health Organization (1973). Report of the International Pilot Siudy of Schizophrenia. WHO: Geneva.

World Health Organization (1979). Schizophrenia: an International Follow-up Study. John Wiley. New York

Yellin, E, Nevitt, M. \& Epstein, W (1980). Toward an epıdemılogy of work disability. Milbank Memorial Fund Quarterly/Health and Society 58, 386-415. 